\title{
Structural learning: Embedding discoveries and the dynamics of production ${ }^{\text {i2 }}$
}

\author{
Antonio Andreoni* \\ Centre for Science Technology and Innovation Policy, Institute for Manufacturing, Department of Engineering, University of Cambridge, \\ United Kingdom
}

\section{A R T I C L E I N F O}

\section{Article history:}

Received January 2012

Received in revised form July 2013

Accepted September 2013

Available online $\mathrm{xxx}$

\section{JEL classification:}

D20

D83

L23

033

Keywords:

Production process

Learning

Structural dynamics

\begin{abstract}
A B S T R A C T
Production and learning of productive knowledge are profoundly intertwined processes as the activation of either process triggers the other, very often implying interdependent transformations. The paper aims to open the 'production black box' by proposing the analytical map of production as a tool for disentangling the set of interdependent relationships among capabilities, tasks and materials. The concept of structural learning is introduced to identify the continuous process of structural adjustment triggered and oriented by existing productive structures at each point in time. Structural learning trajectories allow for the transformation of structural constraints such as bottlenecks and technical imbalances into structural opportunities. Complementarities, similarities and indivisibilities are essential focusing devices for activating compulsive sequences of technological change as well as discovering structurally embedded opportunities. The paper then investigates the tension between structure and agency present in structural learning trajectories, and examines the form it takes in different productive organisations.
\end{abstract}

(c) 2013 Elsevier B.V. All rights reserved.

\section{Introduction}

Production and learning of productive knowledge are profoundly intertwined processes as the activation of either process triggers the other, very often implying interdependent transformations. Production theory has conventionally explained production processes as relation-

\footnotetext{
is This paper develops a line of research initially presented at the DIME workshop "Production Theory-Process, Technology and Organisation: Towards a useful Theory of Production" (LEM, Scuola Superiore Sant' Anna, Pisa 8-9 November 2010). I am grateful to Patrizio Bianchi, Ha-Joon Chang, Mike Gregory, Prue Kerr, Michael Landesmann, Eoin O' Sullivan and Roberto Scazzieri for comments and discussions, and to Guido Buenstorf for comments on an earlier draft of this paper. Finally, I am thankful to two anonymous referees for their valuable comments to the manuscript and their constructive suggestions. The usual caveat applies. The Centre for Science, Technology and Innovation Policy gratefully acknowledges the support of the Gatsby Charitable Foundation.

* Tel.: +44 1223339738.

E-mail address: aa508@cam.ac.uk
}

ships between combinations of productive factors - i.e. input quantities - and certain quantities of outputs. By assuming that producers 'know how' certain inputs may be combined and transformed to obtain certain outputs, production functions do not make any explicit reference to the capabilities needed to perform real production processes. Thus, in standard production theory, there is no production process strictly speaking (Loasby, 1999). Not only is the production process treated as a black box, also the learning dynamics occurring in given production structures are fundamentally ignored. Indeed, economists often treat learning as a costless and automatic process functionally dependent on cumulative output, time, or investment, whose main effect is to reduce average production costs.

A very influential attempt to cope with the fundamental limitations of more conventional production models can be found in the capability theory of the firm, an approach that emerged at the intersection of various research fields, specifically organisational studies (March and Simon, 1993; Penrose, 1959; Richardson, 1960, 1972; 
Teece, 1980; Langlois, 1992; Morroni, 2006; Pitelis and Teece, 2009; Jacobides and Winter, 2012), and institutional and evolutionary economics (Nelson and Winter, 1982; Cohen and Levinthal, 1990; Lundvall, 1992; Dosi et al., 2000), and empirical work in development economics (Bell, 1982; Lall, 1992). With a particular focus on the transformation of cognitive contents and evolving capabilities, these contributions have shown how the knowledge of productive possibilities - i.e. input combinations - has to be complemented by the availability of relevant capabilities for productive tasks being performed. Most notably evolutionary economics has highlighted the complex cognitive dynamics underlying learning processes. It has drawn attention to the multifaceted nature of knowledge, its tacit components as well as the complexities connected to its creation, diffusion, adaptation, adoption and accumulation in organisational 'routines'.

By integrating the above mentioned research streams with structural theories dealing with the complex 'architecture of production', this paper analyses production structures in transformation, examining the embedded constraints and opportunities which are responsible for learning dynamics. From this perspective, learning is understood as a dynamic process triggered and constrained by existing production structures. This means that production structures set the stage for learning dynamics, that is, they prepare human minds for the intuitive discovery of new productive possibilities. The paper also recognises that structures of cognition and structures of production are linked by a bundle of bidirectional transformative relationships.

The goal of the present paper is two-fold. Firstly, the paper embeds different forms of learning such as 'learning by doing' and 'learning by using' in production structures. The paper therefore proposes an 'analytical map of production' as a stylised representation of the system of interrelated tasks through which transformations of materials are performed according to different patterns of capacities/capabilities coordination, subject to certain scale and time constraints (Section 2). Within this new analytical framework, the second contribution of the paper is to introduce the concept of 'structural learning'. In conventional approaches learning is simply described as a cognitive/behavioural dynamic involving production agents. In contrast, in our analytical framework, learning is understood as a process through which 'structural constraints' in production such as bottlenecks and technical imbalances are transformed into 'structural opportunities'. In this context, static and dynamic complementarities, as well as similarities and indivisibilities, are essential focusing devices for triggering compulsive sequences of technological change which permit the discovery of new 'worlds of production' (Section 3). Productive possibilities have to be 'seen', that is discovered and 'actualised' by productive organisations, for structural learning to be feasible. The concept of structural learning highlights a fundamental analytical tension between structure and agency or, more specifically, between productive structures and productive agents (the latter including both individuals and collectivities). Given the same productive structures, structural learning may follow different patterns according to different forms of productive organisation (Section 4). The analytical account of specific historical cases is adopted as main heuristic for disentangling structural learning dynamics.

\section{Embedding learning in production dynamics}

\subsection{Learning in production: a taxonomy}

In their critical review of learning curve studies, ${ }^{1}$ Adler and Clark (1991, p. 270) proposed a fundamental distinction between first-order and second-order learning.

First-order learning refers to those 'learning by doing' processes directly experienced by workers via repetition of productive tasks and the resulting incremental development of expertise. Here, learning is both an individual and collective process as interactions among workers within the firm are integral parts of their learning by doing. The concept of 'learning by doing' expressed in Kenneth Arrow's (1962) seminal contribution captures the Smithian intuition that the accumulation of production experience increases workers' productivity. In particular, Smith mentions three 'different circumstances' responsible for this increase in labour productivity: 'the increase of dexterity in every particular workman', 'the saving of the time which is commonly lost in passing from one species of work to another', and 'the invention of a great number of machines which facilitate and abridge labour' (Smith, 1976[1776], p. 17).

Conventional learning models based on 'learning by doing' and learning curves have been mainly used for explaining productivity growth at the sectoral and macro level (Malerba, 1992, p. 846; Thompson, 2010). In these models, production is treated as a timeless black box and heroic assumptions are made concerning producers' knowledge of the entire spectrum of production possibilities as well as the availability of appropriate productive capabilities. $^{2}$ On the contrary, as the literature on localised technical change (Atkinson and Stiglitz, 1969) has shown, given the local and cumulative character of knowledge, producers are only aware of a limited number of factors composition laws - i.e. proximate production possibilities. Moreover, as shown in the capability literature, production "has to be undertaken by human organisations embodying specifically appropriate experience and skills" (Richardson, 1972, p. 888). ${ }^{3}$

Second-order learning refers to those managerial or engineering actions purposefully aimed at changing the internal structure of production by introducing new technologies, new equipments or investing in workers training. Learning dynamics of this second kind tend to be triggered by a series of factors which are both internal and external to the firm (Malerba, 1992). In terms of the former, not

\footnotetext{
1 The long tradition in learning curve studies is usually associated with the empirical analysis of 'learning by doing' effects on productivity and was initiated by Wright (1936) and his work in the aircraft industry.

2 The stochastic model by Jovanovic and Nyarko (1995) is an exception in providing a microfoundation of Arrow's. . 'learning by doing'.

3 The analytical and technical limitations of the production function models are discussed in Georgescu-Roegen (1970), Scazzieri (1993).
} 
only may the firm specifically invest in search activities and production/technology research aimed at expanding its knowledge base (Nelson and Winter, 1982) but it may also attempt to increase its learning and absorptive capacities themselves (Stiglitz, 1988; Cohen and Levinthal, 1990). As for the latter, in some cases, triggers of learning dynamics are external to the firm and may involve users of final goods (Rosenberg, 1982; Rhee et al., 1984), other producers of intermediate or final goods in the same or in different industries (Lundvall, 1992) or possibly other actors, typically those involved in scientific and technological research (Kline and Rosenberg, 1986).

Rosenberg's (1982, p. 122) concept of 'learning by using' arises from the recognition that "in an economy with complex new technologies, there are essential aspects of learning that are a function not of the experience involved in producing the product but of its utilisation by final users...the performance characteristics of a durable capital good often cannot be understood until after prolonged experience with it". ${ }^{4}$ The related ideas of 'learning by exporting' (Rhee et al., 1984) and 'learning by interacting' (Lundvall, 1992) with upstream and downstream producers develop Rosenberg's fundamental intuition and, thus, may be considered as sub-categories of 'learning by using'. In Lundvall's (1992) framework learning by interacting is a critical feature of societies. Capabilities are collectively developed through social interactions mainly by observing and imitating others' actions as well as by mirroring their attitudes. This is why the organisational design of production processes as well as firms' underlying relational structures can affect people's disposition towards mutual learning and knowledge discovery. Historically, learning by interacting has taken various forms from more cooperative to more competitive ones such as learning by exporting and, thus, though upgrading products characteristics, but also importing and copying machines, recruiting foreign skilled workers and technician exchange, pooling of technology, organisation of expos (industrial exhibitions) and industrial espionage (Chang, 2002; Poni, 2009).

In all these cases, learning dynamics are initially triggered by factors external or internal to the firm that eventually result in the reconfiguration of the firm's internal production structure. Of course this reconfiguration may or may not happen depending on how the firm in question reacts to the internal or external stimuli. All of the above suggests that in order to analyse these compulsive sequences of transformation it is necessary to embed learning dynamics in production structures and to understand in which ways these dynamics are constrained, but also triggered, by existing production structures. Fig. 1 provides a taxonomy of the different forms of learning reviewed above.

\subsection{The analytical map of production}

In mainstream economics, production functions represent complete sets of feasible input combinations for a

\footnotetext{
4 Mukoyama (2006) develops a stochastic model of learning based on this idea.
}

given output; in an isomorphic way, utility functions establish a relationship between combinations of consumption goods and the satisfaction that they provide - i.e. utility. Both production and utility functions are designed to show in the universe of rational choice and equilibrium allocations how the combinations chosen (respectively of inputs and consumption goods) reflect relative prices. Given that conventional production theory does not provide any analytical representation of the internal structure of production processes, qualitative transformations generated by innovations and changes in the technology and structures of production remain completely unexplored. In other words, conventional economics adopts an 'outside the production machine perspective' and, as a result, production and, thus, learning dynamics remain black boxes.

In contrast, the analysis of the internal structure of production combined with a strong emphasis on the representation of the complex system of interrelated production processes in different sectors was at the centre of the classical theories of production. Classical economists focused on the limited availability of non-producible goods, the utilisation problem and the various constraints determined by the production scale and its time structure. There are four main components of the Classical theoretical framework. Francois Quesnay's early formulation of the concept of productive interdependencies called attention to the "circular flow' of wealth production and reproduction (see also Leontief, 1928). Adam Smith's analysis of the internal structure of the pin factory revealed the microeconomic advantages of the division of labour and the macroeconomic conditions on which it is based-i.e. stock of circulating capital flows. Charles Babbage's focus 'on the causes and consequences of large factories' led to the formulation of the law of multiples and, thus, to the discovery of different patterns of proportional utilisation and maintenance of indivisible inputs. Finally, Karl Marx's analysis of different arrangements of production processes highlighted the main features of the modern factory system and thus the working of the so called 'collective machine' (Landesmann, 1986, 1988; Scazzieri, 1993).

In this line, more recently, Wassily Leontief's (1947) input-output analysis and Nicholas Georgescu-Roegen's (1970, 1971, 1990) fund-flow model developed the building blocks for a series of structural approaches to production (Landesmann, 1986; Scazzieri, 1981, 1993; Bianchi, 1984; Morroni, 1992; Landesmann and Scazzieri, 1996; Buenstorf, 2004, 2007). These contributions view a given production process $\mathbf{P}_{\mathbf{r}}(\mathbf{r}=1, \ldots, \mathbf{k})$ as a particular system of interrelated tasks through which a sequence of transformations of materials are performed according to different combinations of flow inputs (such as productive agents and mechanical artefacts) and fund inputs (such as fuel, chemical catalysts and electricity), subject to certain scale and time constraints.

Approaching production from the point of view of structural economics implies an analytical focus on the following set of both quantitative and qualitative coordination problems: (i) how to synchronise and arrange the system of interrelated tasks in time; (ii) how to arrange the production process given the specific properties of materials in 


\begin{tabular}{|c|c|c|}
\hline Learning dynamic & Internal to the firm & External to the firm \\
\hline \multicolumn{3}{|l|}{ First-order learning } \\
\hline Producer-production & Learning by doing & \\
\hline \multicolumn{3}{|l|}{ Second-order learning } \\
\hline Producer-research & $\begin{array}{l}\text { Learning by searching } \\
\text { Learning to learn }\end{array}$ & \\
\hline Producers-science & & Learning from science \\
\hline $\begin{array}{r}\text { Producers-users } \\
\text { Producers - producers }\end{array}$ & & $\begin{aligned} \text { Learning by using } \\
-\quad \text { Learning by interacting } \\
-\quad \text { Learning by exporting }\end{aligned}$ \\
\hline
\end{tabular}

Fig. 1. Learning dynamics: a taxonomy.

transformation; (iii) how to organise and activate the production process by combining different fund inputs each of them endowed with certain capabilities or capacities. ${ }^{5}$ Interdependencies among these coordination problems are pervasive in the sense that for example tasks arrangement depend on both the properties of materials in transformation and firm's availability of capabilities/capacities. ${ }^{6}$

Tasks refer to those production operations that are purposefully performed in a given production process. Each task $\mathbf{T}_{\mathbf{j}}$ (with $\mathbf{j}=1,2, \ldots, \mathbf{j}, \ldots, \mathbf{J}$ ) can be decomposed into elementary operations or clustered in groups of tasks. They can be arranged simultaneously or sequentially in various stages of fabrication $\mathbf{j}$ (with $\mathbf{j}=1,2, \ldots, \mathbf{j}, \ldots, \mathbf{J}$ ), sometimes in a discrete way but sometimes in a continuous way, that is, with or without interruptions. ${ }^{7}$ This last distinction proves to be very relevant as soon as we consider how different forms of production organisation have historically developed different techniques for inventory and storage capacities management (Rosenberg, 1994; Landesmann and Scazzieri, 1996, chap. 8).

Materials refer to what is transformed in the fabrication stages of a production process. ${ }^{8}$ The relationship between materials and stages of fabrication can be represented by a descriptive matrix $\mathbf{M}=\left[\mathbf{m}_{\mathbf{i j}}\right]$ in which any element refers to the material $\mathbf{i}$ (with $\mathbf{i}=1,2, \ldots, \mathbf{n}$ ) that has been transformed in the fabrication stage $\mathbf{j}$ through the execution of the task $\mathbf{T}_{\mathbf{j}}$. At each fabrication stage, given a certain stock of materials available to the productive organisation, only

\footnotetext{
5 Mechanical artefacts present certain production capacities, while each productive agent is characterised by a certain set of production capabilities.

${ }^{6}$ Richardson (1972, p. 885) stresses how "the habit of working with models which assume a fixed list of goods may have the unfortunate result of causing us to think of coordination merely in terms of the balancing of quantities of inputs and outputs and thus leave the need for qualitative coordination out of account".

7 As for the time structure, the material transformation processes can be visualised as a system of pipelines (Landesmann, 1986; see also Morroni, 1992).

8 In the case of 'immaterial production' - e.g. service activities - 'materials in process cannot be identified, at least in the usual sense, and the production process generally takes the form of a close interaction among fund agents, in the course of which some of the characteristics of such agents (and sometimes their capabilities as well) may get transformed (Landesmann and Scazzieri, 1996, pp. 252-253).
}

some materials will be utilised and thus transformed. This implies that for each production process we will observe a certain 'realised' matrix $\mathbf{M}^{*}=\left[\mathbf{m}_{\mathbf{i j}}\right]$, whose internal structure represents all the materials in use in the stages of that production process.

In order to perform a certain system of interrelated tasks through which materials are transformed into final commodities, the production process has to be 'activated' by a series of inputs such as fuel, chemical catalysts, but also machines and productive agents, that is, workers. Flow inputs such as fuel, chemical catalysts, electricity and fertilisers are utilised in certain stages of material transformation but they do not materially constitute the final output of the process as the materials in use do. Flow inputs used in a certain production process can be described through a descriptive matrix $\mathbf{F}=\left[\mathbf{f}_{\mathbf{i j}}\right]$ in which any element refers to the flow input $\mathbf{i}$ that has been consumed in the fabrication stage $\mathbf{j}$ through the execution of the task $\mathbf{T}_{\mathbf{j}}$. For each production process we will observe a certain realised matrix $\mathbf{F}^{*}=\left[\mathbf{f}_{\mathbf{i j}}\right]$.

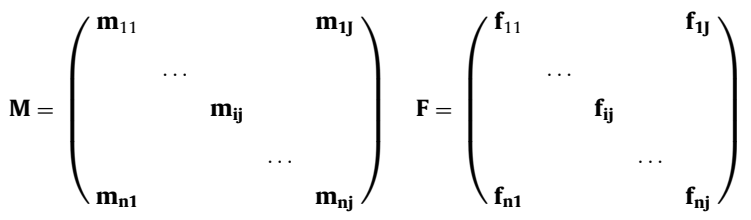

In contrast, fund inputs are both mechanical artefacts such as machines, tools and equipment and productive agents (i.e. workers, supervisors, engineers and managers). Fund inputs maintain their characteristics substantially unaltered during the production process, provided that certain tolerance thresholds are not violated (GeorgescuRoegen, 1970; Landesmann, 1986). Mechanical artefacts present a certain production capacity, while each productive agent is characterised by a set of complementary productive capabilities. By activating some of these capabilities, each productive agent is able to perform a single task or a set of similar tasks (i.e. those tasks which require the utilisation of the same set of complementary capabilities). Although productive agents may learn to perform different tasks, their capabilities are limited so they cannot switch between all productive tasks, especially when complex products are considered. 
Just as we did with materials and flow inputs, we can distinguish between the bundle of capacities/capabilities embodied in a certain set of fund inputs (i.e. potential capacities/capabilities) and the capacities/capabilities actually utilised by the productive organisation in performing a certain set of tasks (i.e. capacities/capabilities in use). ${ }^{9}$ The former is described by the matrix $\mathbf{C}=\left[\mathbf{c}_{\mathbf{i j}}\right]$ while the latter by the matrix $\mathbf{C}^{*}=\left[\mathbf{c}_{\mathbf{i j}}\right]$, where $\mathbf{c}_{\mathbf{i j}}$ denotes the relationship between the capacity/capability $\mathbf{i}$ and the task $\mathbf{T}_{\mathbf{j}}$ performed at the stage of fabrication $\mathbf{j}$. The distinction between the matrix $\mathbf{C}=\left[\mathbf{c}_{\mathbf{i j}}\right]$ and $\mathbf{C}^{*}=\left[\mathbf{c}_{\mathbf{i j}}\right]$ illustrates how the same production process $\mathbf{P}_{\mathbf{r}}(\mathbf{r}=1, \ldots, \mathbf{k})$ can be performed by using different bundles of mechanical artefacts and productive agents, that is, different combinations of production capacity and productive capabilities. However, even when two different productive organisations perform the same process $\mathbf{P}_{\mathbf{r}}$ by combining the same bundle of productive capacities/capabilities, the latter can be employed in different proportions. For example, two firms Firm f $_{1}$ and Firm $_{2}$ can perform the same production process by using the same two fund agents - i.e. workers $w$ and machines $m$ - but in different combinations - for example, one fundinput combination may be more labour intensive than the other.

$\mathbf{C}^{\mathbf{1} *}=\left(\begin{array}{cc}5 \mathrm{w} & 7 \mathrm{w} \\ 1 \mathrm{~m} & 1 \mathrm{~m}\end{array}\right) \quad \mathbf{C}^{2 *}=\left(\begin{array}{cc}1 \mathrm{w} & 2 \mathrm{w} \\ 3 \mathrm{~m} & 3 \mathrm{~m}\end{array}\right)$

Thus, by comparing the two matrices $\mathbf{C}^{1 *}$ and $\mathbf{C}^{2 *}$ we can discover specific features of the production process $\mathbf{P}_{\mathbf{r}}$ performed by Firm 1 and Firm 2 . In particular, the two matrices express different relationships of complementarity among the two fund inputs considered (machines and workers respectively). In our case, the first stage $\mathbf{T}_{\mathbf{1}}$ of the production process $\mathbf{P}_{\mathbf{r}}$ can be performed either by combining one machine with five workers or three machines and one worker (see above). Given these relationships of complementarity between fund inputs and also the fact that machines tend to be tasks-specific and only partially flexible, the kind of combinations of fund inputs that firms can select from the space $\mathbf{C}=\left[\mathbf{c}_{\mathbf{i j}}\right]$ for performing $\mathbf{P}_{\mathbf{r}}$ are limited. Moreover, scaling up the production process not only requires the consideration of these relationships of complementarity but also that a law of proportionality among all the components of the process is satisfied (see below).

Based on Cartwright (1989), it has been noted how very often the capabilities (and capacities) of fund inputs can be expressed in a quantitative form, so that we can assume they are comparable in cardinal space (Landesmann and Scazzieri, 1996, p. 197). One possible quantitative specification of the matrix $\mathbf{C}=\left[\mathbf{c}_{\mathbf{i j}}\right]$ relies on the consideration of the time structure of the production process in relation to the capacity/capabilities in use. The matrix $\mathbf{C}^{*}=\left[\mathbf{c}_{\mathbf{i j}}\right]$ can

\footnotetext{
${ }^{9}$ As has been stressed, this distinction leads us to interpret the emergence of new productive structures within the space of virtual practices as "the outcome of a clustering process that brings about a rearrangement of the primitive elements of productive activity; [thus] structural change may be considered as a case of variation within a spectrum of virtual possibilities" (Scazzieri, 1999, p. 230).
}

be transformed into a matrix of capacities/capabilities use times $\boldsymbol{\Omega}^{*}=\left[\boldsymbol{\Omega}_{\mathbf{i j}}\right]$ where the generic $\boldsymbol{\Omega}_{\mathbf{i j}}$ represents the usetime of the capacity/capability $\mathbf{c}_{\mathbf{i j}}$ in the production process $\mathbf{P}_{\mathbf{r}}$.

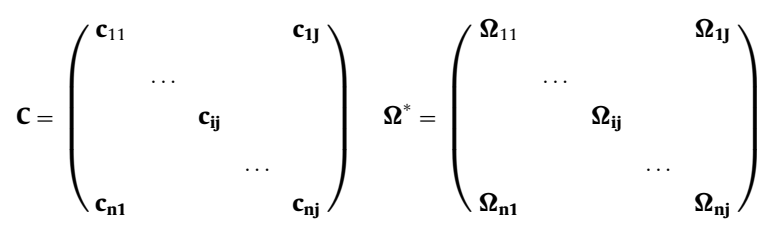

Taking the case in which two different productive organisations perform the same process $\mathbf{P}_{\mathbf{r}}$ with the same combination of fund inputs described by $\mathbf{C}^{*}=\left[\mathbf{c}_{\mathbf{i j}}\right]$, we can compare the matrices $\boldsymbol{\Omega}^{*}$ to discover if one time arrangement of $\mathbf{P}_{\mathbf{r}}$ is more time wasting than another. For example, the reconfiguration of the time structure of $\mathbf{P}_{\mathbf{r}}$ from one in line to one in parallel can reduce the amount of idle time of fund inputs across fabrication stages (see below). Given appropriate transformations such as the one proposed above, as soon as the productive capabilities and capacities become comparable in cardinal space, the capacity-capability ratios can be calculated for each productive task (or groups of tasks) and organised in a matrix. This will elucidate the interdependencies between different kinds of fund inputs. However, the set of interdependencies characterising each production process does not simply involve one subset of its components (here, fund inputs). Instead, each production process requires the coordination of all its components (namely tasks, materials and flow inputs as well as fund inputs).

Interdependencies among components can be visualised by mapping the relationships between capacity/capabilities, tasks and materials. ${ }^{10}$ The entire spectrum of possible combinatorics is represented through the analytical map of production relationships (see Fig. 2). ${ }^{11}$ The mapping from the capacity/capability space $\mathbf{C}$ to the task space $\mathbf{T}$ (i.e. job specification programme) can be determined following different criteria (Landesmann and Scazzieri, 1996). For example different combinations of fund inputs may be relatively more or less adequate for the execution of one task (or cluster of tasks) than another. Also, a reconfiguration of the job specification programme (i.e. different mapping from the space $\mathbf{C}$ to the space $\mathbf{T}$ ) may allow the activation of previously unused fund inputs or the achievement of higher efficiency in the utilisation of the capacity/capabilities in use.

The network of relationships and interdependencies among the spaces $\mathbf{C}, \mathbf{T}, \mathbf{M}$ has to be synchronised over time and according to specific scale requirements determined by the existence of process indivisibilities as well

\footnotetext{
10 For clarity the flow agents are taken out of the picture. The decision to privilege the other three dimensions matrices $C, T$ and $M$ is due to the fact that commonly there are higher degrees of freedom in their combinatorics and the use of flow agents is strictly dependent on the utilisation of fund agents.

11 The concept of 'analytical map of the true [interpersonal] relations' is proposed in Georgescu-Roegen (1976, p. 205) as one possible realisation of the 'entire spectrum of peasant institutions'.
} 


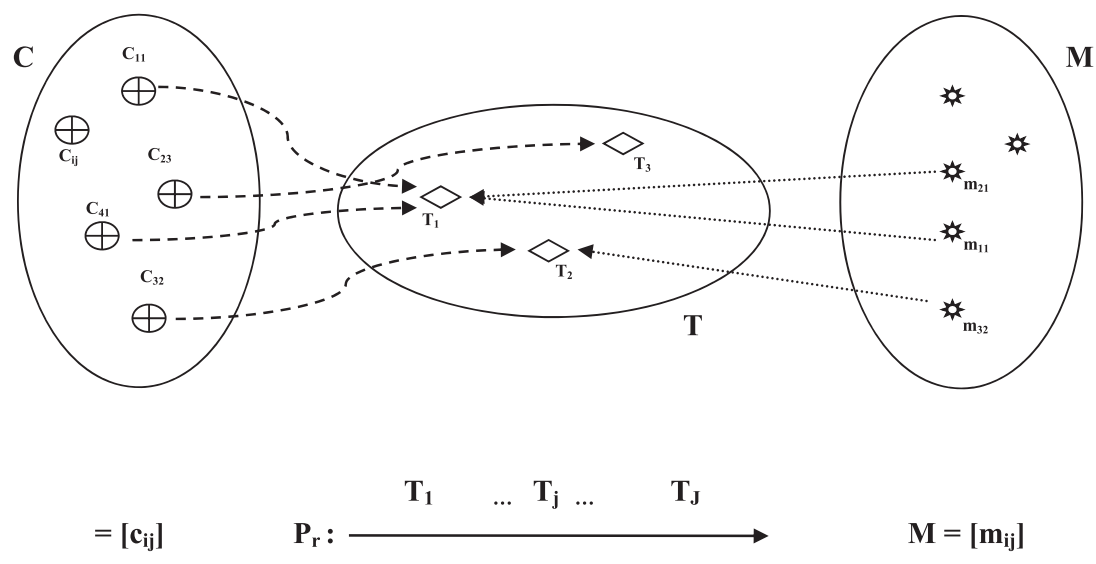

Fig. 2. The analytical map of production relationships.

as indivisible fund inputs. ${ }^{12}$ As for the time structure, synchronisation has to be pursued at three different levels (coordination in the utilisation of fund inputs, arrangement of interdependent tasks over time, and transformation of materials over time). The difficulty of matching the 'time sequencing requirements' of these three dimensions makes perfect synchronisation across the three above mentioned levels impossible and explains the co-existence of patterns of simultaneity or sequentiality. Time gaps and idle time in production processes are thus largely structurally determined and, within the given structure, only partially reducible through various forms of learning (Landesmann and Scazzieri, 1996).

Moving on to indivisibilities, processes are indivisible when they are not 'indifferent to size'. As in the biological world, all individual production processes "follow exactly the same pattern: beyond a certain scale some collapse, others explode, or melt, or freeze. In a word, they cease to work at all. Below another scale, they do not even exist" (Georgescu Roegen, 1976, p. 288). The fact that processes are 'scale-specific' (in other words that they are characterised by upper and lower bounds) implies that conducting a process on a smaller or a larger scale can only be done if a law of proportionality among the components of the process is satisfied. This idea was originally formulated by Charles Babbage's law of multiple. In Babbage's view: ' $[w]$ hen the number of processes into which it is most advantageous to divide [the production process], and the number of individuals to be employed in it, are ascertained, then all factories which do not employ a direct multiple of this latter number, will produce the article at a greater cost' (Babbage, 1835, p. 211).

At the level of the components, limitations in the bundling and unbundling of fund inputs are extremely stringent, while flow inputs as well as materials in transformation are more often divisible. As far as fund inputs are concerned, the existence of indivisible funds of capaci-

\footnotetext{
12 For a comprehensive discussion of the role of time and scale in production see Landesmann (1986), Bianchi (1984), Morroni (1992), Scazzieri (1993), Landesmann and Scazzieri (1996).
}

ties (such as a machine tool with certain scale-determined technical characteristics and specifications) as well as indivisible funds of capabilities (that is, productive agents such as workers and engineers at the shop floor) mean that, for a fund input to be fully utilised, a specific scale of production has to be achieved. For small scales of production, fund inputs would inevitably be underutilised. However, if fund inputs are not too specialised in the execution of some productive tasks, productive organisations can overcome scale constraints by utilising the same indivisible fund inputs for the production of other commodities. Nevertheless these new commodities generally possess a certain degree of similarity as fund inputs are endowed with only a limited set of complementary capacities or capabilities.

\subsection{Embedding learning dynamics}

The structural representation of production provided above now allows us to see some of the many limitations arising from the understanding of learning dynamics as a disembedded process, as is the case with today's mainstream economics (see Section 2.1). To give one example of the main form of first-order learning, Arrow's concept of 'learning by doing' refers to a process involving one subset of the space $C$ (i.e. capabilities of fund inputs such as workers, engineers and managers). In this case, 'learning by doing' is nothing more than an increase in productive capabilities, which generally result in a reduction of capabilities use-times. In other words the execution of the same productive task will require less time due to accumulated experience and as a result the overall productivity of the productive organisation will be increased. However, as we shall see below, our analytical map of production shows how 'learning by doing' does not always imply such productivity increases and it might even lead to the emergence of bottlenecks and imbalances. ${ }^{13}$ 
The reason for this becomes clear as soon as we visualise interdependencies among components, i.e. tasks, materials, flow inputs and fund inputs (and their capacity/capability). The development of increasing capabilities in the execution of a certain set of productive tasks generally implies that certain stages of fabrication will require less time, while other stages remain invariant as a result of constraining factors such as fixed times for material transformation (e.g. time needed for certain chemical reactions) or the scale of other existing fund inputs, in particular machines and equipment. These latter stages of fabrication, given their invariant properties, will appear as bottlenecks in the production process and may end up affecting the entire job specification programme, potentially even neutralising or counteracting the productivity increases of 'learning by doing'.

To give a second example of the importance of understanding learning as embedded we can look at Rosenberg's concept of 'learning by using', the latter being the main form of second-order learning discussed above. The concept of learning by using was developed with reference to 'products involving complex interdependent components or materials'. As a result of the particular industry he focused on, that is, aircraft, ${ }^{14}$ Rosenberg underlined the fact that 'learning by using' implies a "feedback loop in the development stage which, in turn, increases efficiency and/or requires changes in productive techniques" (1982, p. 123). ${ }^{15}$ Rosenberg distinguishes between two kinds of useful knowledge arising from 'learning by using' in both products and processes. Embodied knowledge is that which requires 'appropriate design modifications', while disembodied knowledge "leads to certain alterations in use that require no (or only trivial) modifications in hardware design", although even the latter still "leads to new practices that increase the productivity of the hardware" - for example modification in maintenance practices in the aerospace industry (Rosenberg, 1982, p. 124).

Of course, these two forms of 'learning by using' are intertwined. By generating new embodied knowledge, 'learning by using' in fact facilitates the discovery of new forms of disembodied knowledge and even makes them necessary. What is implicitly suggested here is that 'learning by using' may trigger the rearrangement of the job specification programme. This occurs because of the new productive tasks and fund inputs required to cope with design modifications (embodied knowledge), or as a result of alterations in productive practices whose performances depend on the rearrangement of fund inputs available (disembodied knowledge).

situations' (Arrow, 1962, p. 155). However, the effects of 'evolving stimuli' in the transformation of productive structures are not analysed given the lack of an analytical map of production.

14 Even today aircraft are among the most complex products, composed of almost 6 million parts (by way of comparison a car is typically composed of just 6 thousands parts).

${ }^{15}$ In this respect, see also Hippel von (1988) whose contribution links the learning by using dynamics to product diversification patterns. Also, Kline and Rosenberg (1986) presents a 'chain-linked model' where feedback loops in the innovation process are recognised as key factors.
The first case is more clearly detectable as it requires definite design modifications (i.e. technological improvements) while the second set of transformations tend to be under-estimated as they do not call for the introduction of any new fund inputs. The analytical map of production allows us to understand how a production process may be qualitatively transformed even without equipping the productive organisation with new fund inputs or without transforming the existing ones. Instead, the production process may be transformed just by rearranging fund inputs among the system of tasks which have to be performed or by synchronising tasks in a different way over time. In fact there are various ways of combining elementary operations into new tasks or clustering existing tasks in new ways. Once again the extent to which this can be done depends on the capacities/capabilities embedded in funds inputs and their degree of utilisation, as well as on the properties of the materials in transformation and on time arrangements.

Learning processes are intrinsically heterogeneous and occur through time at several nested levels of production, the latter being structurally determined by productive interdependencies. ${ }^{16}$ As soon as we attempt a restructuring of 'learning by doing' or 'learning by using', it becomes obvious that the majority of existing studies focus their attention on what triggers the learning process or what its output is. The process per se not discussed. In other words, the conventional analysis of learning ends exactly where the learning process starts. Even when there is a more detailed investigation of learning dynamics in production, as in the work of economic historians (Rosenberg, 1969, 1976, 1979, 1982; Noble, 1986; Piore and Sabel, 1984; Mowery and Rosenberg, 1998; Mokyr, 2002; Landes, 2000; Poni, 2009), production structures are generally seen only as constraints that productive agents overcome through problem-solving activities and changes in productive techniques. For example, Mokyr (1990, p. 9 italics added) argues that '[t]echnological change involves an attack by an individual on a constraint that everyone else has taken as given'.

However, as we shall see below, an analytical account of a number of historical cases allows us to understand how existing and evolving production structures are not just constraints. Instead, existing production structures orientate productive agents towards certain learning trajectories and allow them to discover structurally embedded opportunities. As shown by Hicks (1969), the adoption of an analytical approach to economic history can be a vehicle

\footnotetext{
16 Another aspect that conventional approaches tend to forget is that 'learning in time' can proceed at different speeds according to the time required for reconfiguring the production structure or according to the time knowledge requires to flow (i.e. be disseminated and absorbed) throughout the production organisation or at the inter-firm level. In other words the problem is not only 'what to learn' or 'how to learn to learn' but also 'how to learn faster'. As shown by Dodgson (1991), the differential ability in learning quickly about technological opportunities is a crucial determinant especially in those sectors (e.g. biotechnology) characterised by an uncertain and generally rapid process of transformation.
} 
for developing a 'quasi-theory', that is to say a stylised representation of economic facts through which theories can be developed.

\section{Structural learning: an analytical framework}

\subsection{Learning in a structured space: an analytical account of historical cases}

The analytical map of production relationship elucidates firstly the 'architecture of complexity' in production (Simon, 1962; Buenstorf, 2005) and secondly, the fact that learning dynamics are realised in a 'structured space' over time. This means that learning in production is not simply a process occurring as a result of cognitive dynamics; rather it is also a process triggered and orientated by structural dynamics. The latter open up the possibility of transforming 'structural constraints' such as bottlenecks and technical imbalances into 'structural opportunities'. As highlighted in structural analyses of production (see above), coordination problems in the space of capacity/capabilities, materials and tasks may be solved in multiple (albeit interdependent) ways. In other words, there are 'worlds of production', that is, a variety of production arrangements ('world of possibilities') that are feasible even under same sets of contextual conditions (Salais and Storper, 1997).

'Worlds of possibilities' permit the transformation of production processes and their outcomes - i.e. process and product innovations (Sabel and Zeitlin, 1997). Of course saying that there are multiple possibilities should not blind us to the fact that bottlenecks, materials properties or technical imbalances are all pervasive constraints. In fact, discovering these possibilities, given certain structural constraints, is the very essence of what I call the structural process of learning. The concept of structural learning is introduced here to identify the continuous process of structural adjustment and transformation of production 'triggered' and 'orientated by' existing and evolving production structures. Static and dynamic complementarities, as well as similarities and indivisibilities, are essentially focusing devices for activating compulsive sequences of technological change and discovering new production possibilities at the firm and inter-firm level.

We will now move to an analytical account of historical cases in which "[c]omplex technologies create internal compulsions and pressures which, in turn, initiate exploratory activity in particular directions" (Rosenberg, 1969, p. 4). This historical analysis is the first step towards disentangling those structural dynamics that prepare the setting for learning and those specific factors triggering learning processes in production. The second step is to identify a number of structural learning trajectories and illustrate them with an analytical map of production relationships. The third step will be to re-link dynamics occurring at the level of production structures with those occurring at the level of the structures of cognition in productive organisations. As we shall see, this third step will allow us to show the analytical tension between structure and agency in learning dynamics and also elaborate how structure and agency are linked by a bundle of bidirectional transformative relationships (Bourdieu, 1972). ${ }^{17}$

Rosenberg (1969) identifies three main 'inducement mechanisms' of learning, namely technical imbalances or bottlenecks, labour-saving/uncertainty-reducing machines and substitutes or alternative sources of supply of fund and flow inputs or materials. A number of historical examples will help to illustrate this point. In 1900 the machine tool industry was revolutionised by the introduction of high-speed steel which allowed an increase in the hardness of cutting tools. However "it was impossible to take advantage of higher cutting speeds with machine tools designed for the older carbon steel cutting tools because they could not withstand the stresses and strains or provide sufficiently high speeds in the other components of the machine tool" (Rosenberg, 1969, p. 7; see also Andreoni and Gregory, 2013). As a consequence, transmissions, control elements and other machine tool components had to be redesigned and this change "in turn, enlarged considerably the scope of their practical operations and facilitated their introduction into new uses" (Rosenberg, 1969, p. 8). This is a typical example of a technical imbalance leading to changes in complementary processes as well as components, that is, tasks, materials and capabilities/capacities. It highlights how a technical constraint can actually activate a process of exploration and searching in which "the size of the discovery need bear no systematic relationship to the size of the initial stimulus" (Rosenberg, 1969, p. 9).

Indeed, the initial technical imbalance in a certain industry may trigger structural learning processes in other industries and sectors. In the early nineteenth century US agricultural sector, before tractors were introduced, John Deere revolutionised agricultural production by inventing the steel plow (Andreoni, 2011a,b). A biological constraint triggered the introduction of steel plows, but also of other complementary tools made with the same or different materials according to specific task requirements. Traditional wood plows could not plow the rich soil of the Middle-West without breaking. At that time given the scarcity of steel and the need to import it from Great Britain, John Deere made his first plow out of an old blade saw. After a series of tests on different types of soil, the new steel plow was ready to be absorbed into the "crop-growing technique' adopted at that time. In turn, the introduction of the steel plow triggered new complementary discoveries as well as the application of the same new material to other equipments requiring the same hardness. In fact, as recognised by Rosenberg (1979, p. 37), 'the substitution of new materials (e.g. aluminium and rust-resistant steels) for old ones, improved techniques of friction reduction (lubrication and roller bearings) have led to a considerable extension of the useful life of a wide range of capital equipment' as well as to other 'cumulative improvements'.

\footnotetext{
17 At the centre of Bourdieu's analysis there is the dialectic between 'externalising the internal' and 'internalising the external' which attempts to go beyond precisely the same tension.
} 
Thus, the process of structural learning in a given sector may develop an intersectoral character. In other words, complementarities (as well as innovations suitable for similar tasks performed in other productive activities) may spread from one sector of an economic system to another sector triggering a specific form of structural learning which we label here intersectoral learning. The latter expression identifies a dynamic process of interlocking and mutual reinforcing technological developments which links the innovative patterns of two or more sectors in a relationship of complementarity and/or similarity. In sum, technical complementarities among fund inputs or the application of an innovation - e.g. a new material with certain properties - in the execution of a broad set of similar productive tasks are the fundamental dynamics underlying the learning processes considered by Rosenberg.

It is not just constrained posed by existing technical processes that can work as triggers for structural learning dynamics: social process can function in this way as well. In the Poverty of Philosophy Karl Marx observed how "after each new strike of any importance there appeared a new machine" (n.d.: 134; first source Rosenberg, 1969). The threat of strikes introduces a critical element of uncertainty to the supply of labour and strongly affects the delicate time structure of a production process, thereby promptly the invention of new labour-saving machines. Social changes induce the invention or discovery of new machines and this in turn sets off a further train of changes.

Robert's self-acting mule, the Jacquard punching machine and the introduction by the British Government of the 'American System of Manufacturing' in the gun making industry in 1854, are all cases in which the invention or acquisition of a new more powerful machine is just the first step in a subsequent process of structural learning (Rosenberg, 1969; see also Chang, 2002). All these cases highlight how when a new machine becomes available production that was technically feasible but not economically convenient becomes possible. This possibility depends on increasing the scale of complementary machines or in the re-arrangement of workers in the production unit, provided that they can perform a certain set of similar productive tasks.

Together with the above mentioned inducement mechanisms identified by Rosenberg, the need/opportunity of increasing the scale of production is another factor triggering processes of structural learning. For example complementary innovations such as refrigerators, railways and steamships affected the reduction of transportation costs, increased the degree of regional specialisation and opened the opportunity to benefit from scale technology expansions and from specialisation in a limited set of productive tasks performed at high productivity standards. Indeed, as soon as the scale of production increases 'a shifting succession of bottlenecks' will emerge. Focusing on them, engineers will start exploring new possible configurations of the production process, which may lead to serendipitously discovering 'singleton techniques' (Mokyr, 2002). Problems related to scale constraints, which arise both from indivisible fund inputs and indivisible processes, may trigger the discovery of innovative (structural as well as organisational) configurations of production processes (Andreoni and Scazzieri, 2013). A good example of this is the typical problems faced by small farmers and small firms when trying to gain access to indivisible fund inputs such as machines and other equipment. Historically fund inputs indivisibilities as well as scale invariant processes have triggered institutional innovations such as 'renting/sharing' solutions implemented by producer cooperatives (Lissoni, 2005) as well as forcing productive agents to rearrange job specification programmes.

\subsection{Structural learning trajectories}

The historical cases document how inducement mechanisms of learning dynamics, and the resulting 'compulsive sequences' of transformations, are embedded in and triggered by existing production structures at each point in time. Specifically complementarities and similarities among tasks or materials, as well as fund inputs indivisibilities, have been crucial focusing devices in structural learning dynamics. The analytical account of these historical cases leads to the identification of three fundamental structural learning trajectories. Given a certain bottleneck or technical imbalance in production, the first two structural learning trajectories are triggered by the existence of similarities and of complementarity among materials, tasks and fund inputs. The third structural learning's trajectory is triggered by the existence of indivisibilities in production.

The fundamental intuition behind the first two structural learning trajectories may be found in Richardson's $(1960,1972,2003)$ observation that different forms of inter-firm cooperation we see arise from different patterns of similarity and complementarity among productive activities. ${ }^{18}$ Richardson breaks down the production of each final commodity into various stages or activities, each of them executable by different types of firms. "Activities which require the same capability for their undertaking" are called similar activities (Richardson, 1972, p. 888). On the other hand, activities are complementary "when they represent different phases of a process of production and require in some way or another to be coordinated [...] both quantitatively and qualitatively" (Richardson, 1972, pp. 889-890). Building on this dichotomy, Richardson explains how the complex and interlocking clusters, groups and alliances of firms we observe are in reality different responses to the same problem: the need to coordinate "closely complementary but dissimilar activities". ${ }^{19}$ As firms cannot accumulate all the capabilities required for performing a broad set of dissimilar activities, they will specialise in a few activities and cooperate with those firms specialised in closely complementary activities. Principles of similarity and complementarity also operate at the firm level and are responsible for distinct structural learning trajectories.

\footnotetext{
18 See also Ménard (2004), Gibbons and Roberts (2011), Garnsey and McGlade (2006).

19 This analytical point is developed in Section 4 with respect to the different forms of production organisation.
} 


\subsubsection{Structural learning trajectory triggered by similarities}

Overcoming a productive constraint by introducing a new set of tasks, capabilities or materials may induce the same or other firms to adopt the same set of tasks, capabilities or materials for overcoming a similar constraint, in the same or other kind of productive processes. As documented by Rosenberg (1963, pp. 422-423, italics added) "industrialisation was characterised by the introduction of a relatively small number of broadly similar productive processes to a large number of industries. This follows from the familiar fact that industrialisation in the nineteenth century involved the growing adoption of a metal-using technology employing decentralised sources of power". Furthermore, discovering a new way of performing a certain task affects all those productive processes in which similar tasks are performed. This explains why "many of the benefits of increased productivity flowing from an innovation are captured in industries other than the one in which the innovation was made" (Rosenberg, 1979, p. 41; see also Usher, 1954). ${ }^{20}$

Many examples might be provided which highlight the existence of technological linkages among apparently uncorrelated products such as guns, sewing machines, bicycles, motorcycles, and automobiles. Among the many historical examples the development of the universal milling machine by Brown and Sharpe is, perhaps, the most outstanding example of a machine which was initially developed as a solution to a narrow and specific range of problems and which eventually had enormous unintended ramifications as the technique was applied to similar productive processes over a wide range of metal-using industries' (Rosenberg, 1963, p. 432, italics added).

In the specific case of firms whose production process consists of a system of similar tasks, the discovery of a new way of performing a certain task or the introduction of a new material implies a complete reconfiguration of the entire process. However, as in this specific case productive agents would already be endowed with similar kinds and amounts of capabilities, they will be substitutable and can be arranged in many different ways across time. The production process of more complex products (or components) tends to assume the form of a system of dissimilar tasks. Indeed, complex products are defined as those "composed of many subsystems that interact in complex ways" (Rosenberg, 1982, p. 136). In the case of complex products requiring the performance of closely interdependent dissimilar tasks, intra and inter-firm complementarities will be pervasive.

\subsubsection{Structural learning trajectory triggered by complementarities}

"[I]nnovations hardly ever function in isolation" (Rosenberg, 1979, p. 26). The theoretical framework we have constructed allows us to analytically specify and explain this intuitive insight of Rosenberg's. Innovation

\footnotetext{
${ }^{20}$ This analytical point will form the basis of our discussion in the Third Essay of the concept of intersectoral learning.
}

occurs in this bunched fashion because of the utilisation and the productivity of fund inputs (i.e. machines with certain capacities or productive agents with certain capabilities) both critically depend on the simultaneous availability of complementary fund inputs. Complementarities among fund inputs may trigger direct learning dynamics, or learning dynamics over time. Direct learning dynamics occur when one fund input makes the functioning of another fund input possible or more efficient. Learning dynamics over time occur when one fund input makes the functioning or introduction of other fund inputs possible over time.

In the specific case of a production process constituted by a system of dissimilar tasks, fund inputs performing a specific task in one stage of fabrication are combined with others performing other tasks in other stages of fabrication in a relationship of complementarity rather than of substitutability. Now if tasks are very dissimilar and complex, productive agents (or even entire productive organisations) have to specialise in the execution of only one task, or even in performing elementary operations of more complex tasks. In this case, a number of processes of the same type can be organised in series (also called in sequence) so that specialised productive agents (or organisations) can perform the task in which they are specialised without long periods of inactivity. Discovering this possibility and applying it to the production process allows firms to reduce time wastage as productive agents will shift over time from one process to another.

Additionally, according to the degree of decomposability of a given production process, firms may decide to adopt a modularisation strategy (Langlois, 2002; Buenstorf, 2005). Interestingly, in the case of productive processes composed of closely complementary but dissimilar tasks, modularisation may guarantee static efficiency at the cost of dynamic efficiency. This problem occurs because modularisation tends to reduce the number of learning trajectories triggered by complementarities.

\subsubsection{Structural learning trajectory triggered by indivisibilities}

Indivisible fund inputs and materials as well as scaleinvariant tasks (or processes) impose a proportionality path on all transformations of the internal structure of production (see above the reference to Babbage's law of multiples). This means, for example, that if a certain indivisible fund input (e.g. a new machine) is adopted, then, the firm has to reconfigure the job specification programme in such a way that scale economies generated by the use of the new machine are exploited and potential bottlenecks and time or material wastes are avoided.

The existence of indivisibility might also trigger incremental innovations both at the technological and organisational levels. For example adopters of the new indivisible input (or scale-invariant task) "could invent around the new machine and remove those technological constraints that limit their ex ante or ex post size. [...] Alternatively they could attack it directly by finding the way to split the different functions that the original innovation performs jointly, thus decomposing the latter into a few (possibly compatible) modules, each of them 
being cheaper than the original item" (Lissoni, 2005, p. 364 , italics added). Indivisibility-led innovations may also affect the way in which indivisible fund inputs are acquired and adopted and, thus, production is organised. As documented in Paul David's (1966) analysis of smaller firms and their ways to deal with indivisibilities, another form of innovation triggered by indivisibilities is the creation of producers' consortia and cooperatives or pro-renting innovations.

Structural learning trajectories triggered by indivisibilities also interact with those triggered by similarities and complementarities (see above). Specifically, indivisibilities 'shape the form' of those learning trajectories triggered by similarities and complementarities. This means that the application of new indivisible fund inputs and materials to similar production activities (in the same or different sectors) will introduce in the new production context in which they have been applied a new indivisibility. The latter will reshape the overall job specification programme and the scale of the production process (when its introduction is not too costly). As for the case of complementarities, at the firm level they mainly arise in three ways: (i) among indivisible fund inputs or materials, (ii) as a result of scale-invariant processes, and finally, (iii) among different production processes when the combined execution of scale-invariant tasks reduced the costs of each production process (i.e. economies of scope, Morroni, 1992).

\subsubsection{Analytical map of structural learning trajectories: an illustration}

One of the possible ways to visualise how these three structural learning trajectories interact is to make use of the analytical map of production relationships we developed earlier. Different examples can be inserted into the analytical map of production relationships (see figure 3). Let us consider the following illustrative case. The acquisition of a new fund input $\mathbf{c}_{53}$ (e.g. a new machine introduced through technology transfers or a traditional machine transformed by small improvements) can trigger a cascade process of production reconfiguration. The task $\mathbf{T}_{2}$ has to be decomposed into two tasks $\left(\mathbf{T}^{\prime}{ }_{2}\right.$ and $\left.\mathbf{T}^{\prime}{ }_{3}\right)$ while the obsolete fund input $\mathbf{c}_{23}$ can be dismissed. The discovery of a new material $\mathbf{m}_{54}$ requires the execution of a new task $\mathbf{T}_{4}$ to be transformed. The scale of fund input $\mathbf{c}_{41}$ has to be changed, given the introduction of a new indivisible fund input $c_{53}$. A previously unutilised capabilities fund $\mathbf{c}_{64}$ is activated so a new complementarity with the new material $\mathbf{m}_{54}$ has been discovered.

These dynamics may be also analysed by adopting the virtual matrix $\mathbf{C}=\left[\mathbf{c}_{\mathrm{ij}}\right]$ and $\mathbf{C}^{*}=\left[\mathbf{c}_{\mathrm{ij}}\right]$ (see above). Here, through the process of structural learning, some relationships of complementarity among funds inputs will end, others will change (although maintaining the same proportions) while others still will be completely transformed. A similar idea is presented by Simon (1962, p. 475) when he suggests that, given a hierarchical system of interdependencies, the architecture of complexity may be disentangled by adopting what he calls a nearly decomposable matrix.

\subsection{Structures of production and structures of cognition}

The cascade process of reconfiguration triggered by structural learning dynamics cannot be thought of as an automatic one. In order to react to structural stimuli and feedback loops, they have to be 'seen' (that is, discovered) by productive agents and 'used' by productive organisations for reconfiguring their internal processes. ${ }^{21}$ Poni's comparative study of the silk industry in Lyon and Bologna clearly illustrates this point when he highlights how feedback must "end in the hands of the right persons [as feedback management] require capabilities and knowledge of techniques which are not necessarily available in the right moment, in the right sector, in the right hands" (Poni, 2009, p. 297; my translation).

The likelihood that opportunities embedded in productive structures are seen by productive agents and used by productive organisations depends on three set of issues:

(i) the individual and collective cognitive dynamics through which opportunities are discovered;

(ii) the collective capabilities of productive organisations to transform production structures (provided that certain new opportunities have been discovered);

(iii) the specific form assumed by the productive organisation. We will discuss the first issue in the present section and then the last two conditions in the following section.

To return to the issue of individual and collective cognition dynamics, psychologists (e.g. Kellogg, 1995) and experts in behavioural and organisational studies (Simon, 1986) have done a great deal of research on the mechanisms responsible for agents' memorisation. Most interestingly they have looked at agents' embodiment of perceived stimuli and past experiences such as various forms of 'analogical thinking'. Moreover the same studies have elucidated how the positions held in certain structures affect agents' understanding and representation of stimuli and experiences (for a review see Buenstorf, 2004).22 This set of results have been synthesised by March and Simon (1993, p. 335 italics added) when they stress how "[p]roblems in learning from experience stem partly from inadequacies of human cognition habits, partly from features of organisation, partly from characteristics of the structure of experience". In this passage there is a clear emphasis on the collective and structural dimensions of cognition and learning.

The collective character of learning was originally highlighted by Herbert Simon (1957) in his analysis of the bounded rationality problem. Simon introduced the idea that individuals' learning is socially constructed, in other words, that ' $[w]$ hat an individual learns in an organisation

\footnotetext{
21 The mapping of the reconfiguration problem, as done in Fig. 3, is an heuristic for tracking complex evolving interdependencies.

22 Buenstorf (2007) is one of the few contributions addressing these analytical conjunctures by posing the building blocks of an evolutionary theory of production.
} 


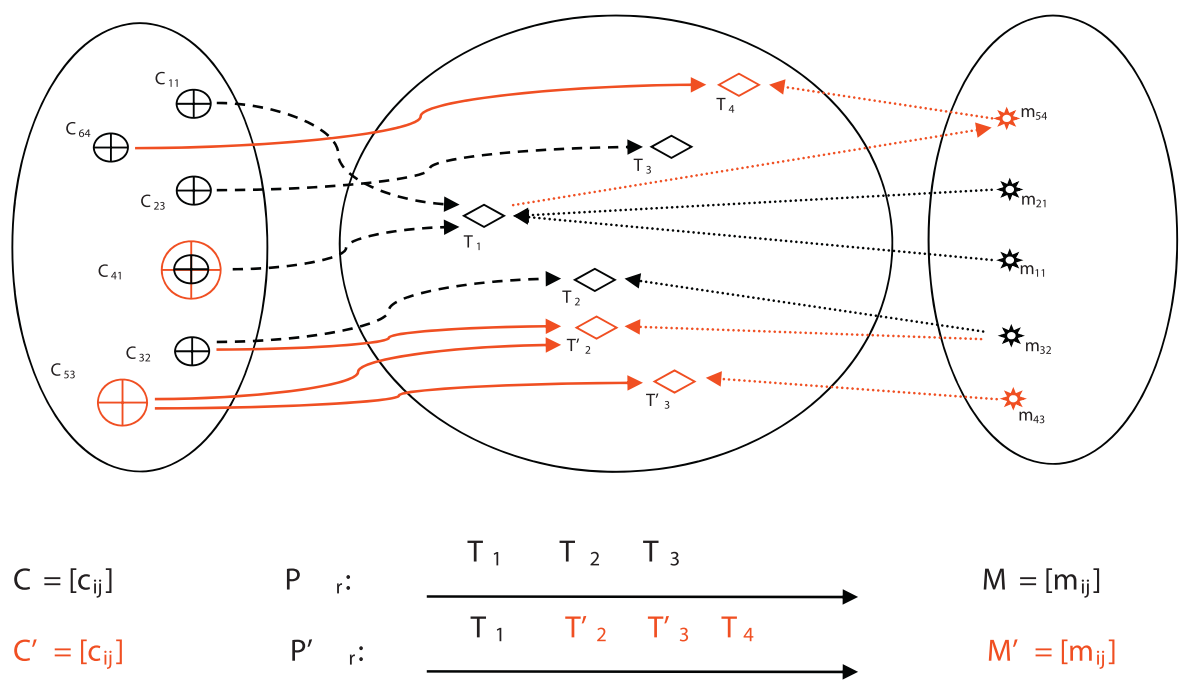

Fig. 3. Structural learning trajectories.

is very much dependent on what is already known to (or believe by) other members of the organisation and what kinds of information are present in the organisational environment' (Simon, 1991, p. 125). However, as the collective and thus organisational dimension affect human cognition habits, also the structure of experience does. Now a fundamental analytic tension arises here. Structures of production and structures of cognition are linked by a bundle of bidirectional transformative relationships. On the one hand, agent's cognitive structures are continuously shaped by evolving productive structures (given that the former are embedded in the latter). On the other hand, productive agents may take different decisions and reshape productive structures in a unpredictable way (based of course on certain stimuli coming from productive structures).

It will now become possible to see how the three structural learning trajectories discussed above provide agents with focusing devices to decompose the complex architecture of production and select from amongst the set of possible learning trajectories the one they want to follow. In order to explain this process we make use of the work of Simon (1962, p. 468) and conceptualise the production process as a complex system "composed of interrelated subsystems, each of the latter being, in turn, hierarchic in structure until we reach some lowest level of elementary subsystem". When faced with the "architecture of complexity', Simon (1962, pp. 472-473) suggests that "[P]roblem solving requires selective trial and error" and adds that "[ $\mathrm{t}]$ he selectivity derives from various rules of thumb, or heuristics, that suggest which paths should be tried first and which leads are promising". Thus seen, the complementarities, similarities and indivisibilities embedded in production structures can be seen to trigger and orientate cognitive dynamics in Simon's sense, giving rise to what we have called here structural learning dynamics.

Now from a methodological standpoint, in order to decompose the complex architecture of production and investigate further these structural learning dynamics, the paper has maintained a separation between two fundamental levels of analysis (Simon, 1962; Rosenberg, 1963; Pasinetti, 2007; Andreoni and Scazzieri, 2013). As suggested by Luigi Pasinetti's (2007, p. 255) separation theorem "it is possible to disengage those investigations that concern the foundational bases of economic relations - to be detected at a strictly essential level of basic economic analysis - from those investigations that must be carried out at the level of the actual economic institutions, which at any time any economic system is landed with, or has chosen to adopt, or is trying to achieve".23 A similar methodological approach was envisioned by Rosenberg (1963, p. 440) when he noted: "an analytical explanation of many of the technological changes in the manufacturing sector of the economy may be fruitfully approached at the purely technological level. This is not to deny, of course, that the ultimate incentives are economic in nature; rather, the point is that complex technologies create internal compulsions and pressures which, in turn, initiate exploratory activity in particular directions". The next section investigates structural learning dynamics from the level of the actual production organisations. ${ }^{24}$

\footnotetext{
23 See also Simon (1962) on techniques for decomposing the architecture of complexity and Scazzieri (1993, pp. 11-13) on the distinction between social and technical division of labour.

24 Of course this essay recognises "the importance of the immaterial side of production, that is, of the complex network of cognitive rules and practices, customs and social norms from which production is made possible" (Landesmann and Scazzieri, 1996, p. 4). However here we have focused our attention on the often-overlooked role that production structures play in triggering and orientating learning dynamics of the cognitive kind. In the concluding section the paper addresses the issue of how structural learning trajectories, given the same set of structural stimuli, may be framed in different ways by different organisations according to their collective capabilities and the specific organisational form assumed.
} 


\section{The organisation of production and structural learning}

As we have already discussed, opportunities embedded in the productive structure not only have to be 'seen' by productive agents but also have to be captured and actualised by production organisations. The latter may take various forms in different historical contexts and are endowed with different organisational capabilities to operate as collective entities. As stressed by Luigi Pasinetti (2007, p. 271) “[The production paradigm cannot] abstract, as the models of exchange usually do, from historical specificities, since the kind of institutions that shape an industrial society, besides being far more complex, are inherently subject to changes induced by the evolving historical events, much more extensively than those that shaped the era of trade". In this respect, the notion of forms of production organisation captures the different ways in which "coordination problems have been resolved in particular circumstances, taking into account the state of technological knowledge, the evolution of patterns of demand, natural resources and environmental constraints, etc." (Landesmann and Scazzieri, 1996, p. 218; see also, Morroni, 2006; Jacobides and Winter, 2012). The emergence and disappearance of different forms of production organisation testify that the coordination of tasks, productive agents and materials in transformation can follow different patterns according to specific objectives and constraints (see above). Thus, the 'virtual coordination patterns' actualise as 'real responses' to specific historical and contextual circumstances.

In evolutionary economics the collective capabilities of production organisations have been referred to as 'organisational capabilities' (Nelson and Winter, 1982; Amit and Schoemaker, 1993; Dosi et al., 2000). Organisational capabilities are a particular form of know-how which enable organisations to perform their "basic characteristic output actions - particularly, the creation of a tangible product or the provision of a service, and the development of new products and services" (Dosi et al., 2000, p. 1). In this context, for an organisation 'to be capable of something [it has] to have a generally reliable capacity to bring that thing about as a result of intended action' (Dosi et al., 2000, p. 2). To the opposite of organisational routines, which are characterised by a high degree of tacitness, automaticity and repetitiveness, capabilities are developed and deployed by organisations as a result of intentional and conscious decisions. However, as routines constitute one of the building blocks of organisational capabilities as well as individual skills contribute to the emergence of organisational routines, these two functional features of organisations - i.e. organisational capabilities and routines - remain strongly intertwined. Here, the central point is to understand contextually to what extent a capability became routinised and or a routine emerge as a distinct capability. In this respect organisational routines that are characterised by a high degree of tacitness, automaticity and repetitiveness are problematic since structural learning dynamics will tend to destroy old routines and introduce new ones.

By definition structural learning is not an individual process, since productive agents (and/or productive units understood as organised sets of production agents) are intrinsically interdependent. In other words, to different degrees, structural learning involves a number of interdependent tasks, as well as fund inputs and materials in transformation. Thus structural learning is a systemic process, which means that firms have to be endowed with organisational capabilities to manage all the transformations entailed by structural learning trajectories. To the extent that learning trajectories are variously triggered by similarities, complementarities and indivisibilities, firms will require increasing amounts of organisational capabilities in order to reconfigure the analytical map of production relationships. However, the organisational capabilities required will be different according to the specific organisational form adopted by the firm and this will affect possibility of following certain structural learning trajectories.

\subsection{The job-shop, the putting-out system and the factory model}

Not all forms of production organisation - such as the job-shop, the putting-out system or the traditional factory model - are suitable for transforming certain structural 'constraints' into structural 'opportunities' along certain structural learning trajectories. Thus it may happen that certain organisational forms have to be abandoned for new ones. Otherwise we can face situations in which structural learning trajectories that are feasible will never been realised in historical time. ${ }^{25}$

For example, the job-shop model, adopted in the craft system, is a form of production organisation characterised by (i) multi-task productive agents performing similar tasks and (ii) a 'stop and go' process of material transformations. These two features provide the craft system with high flexibility and adaptability in solving unexpected problems, although low capacity in satisfying increasing levels of demand. With the exception of a few productive agents who coordinate the entire production process, in the job-shop model productive agents tend to be highly substitutable and each of them is only capable of performing the same limited set of tasks. Given this organisational form, structural learning dynamics will tend to follow patterns of diversification in similar activities. These do not require any investment in the acquisition of new fund inputs endowed with different capacities/capabilities.

Clearly, this organisational form is limited by a number of quantitative (e.g. scale) and qualitative (e.g. specialisation) constraints. Thus in the case of increasingly complex products whose production requires the performance of dissimilar but closely complementary activities, firms using the job-shop model may have to change their organisational forms because non-specialised multi-tasks agents cannot make such products. The same problem may arise when firms attempting to satisfy increasing levels of demand have to introduce specialised fund inputs in order

\footnotetext{
25 Similarly, Henderson and Clark (1990) focus on the interplay between structural features of production and organisational capabilities in the context of architectural innovations.
} 
to scale up processes (according to specific laws of proportionality). Production processes operating at different scales may then require different organisational forms.

The putting-out and the traditional factory model are responses to some of the above-mentioned structural constraints faced by the job shop model (Landesmann and Scazzieri, 1996). The putting-out model (also known as Verlagssystem) is structured as a network of separate 'specialised workshops', each of them performing a limited number of tasks related to a specific stage of fabrication. Very often the workshop (or the merchant) executing the final stage of production is responsible for the coordination of the different production processes performed in the different workshops. Sometimes they are also involved in previous stages of fabrication, for example by assuring the provision of raw materials (Hicks, 1969). Here, given the high degree of interdependence among productive tasks performed by each member of the network as well as the fact that each workshop is highly specialised, we observe overlapping structural learning trajectories triggered by indivisibilities and new complementarities.

In contrast, the traditional factory model was developed as a concentrated form of production in which complex productive tasks were subdivided in an increasing number of elementary operations performed by highly specialised productive agents inside the same production organisation. Historically the traditional factory model was adopted in the automotive industry at the time in which Ford and General Motors were dominating the global car production. Here, both workers and machines and, thus, their capabilities and capacities, are coordinated in a way that guarantee their full and continuous utilisation in executing networks of dissimilar tasks (Landesmann, 1986, p. 294). By increasing the scale of production, in the factory context indivisible funds can be more efficiently utilised and, thus, both economies of scale and scope achieved. In the traditional factory context, structural learning dynamics triggered by indivisibilities tend to be pervasive. This last point was outlined in the 'Maxcy-Silberston curve' in the specific context of Western vehicle manufacturers.

\subsection{The lean production system}

Just as the factory model developed as a response to a series of structural constraints characterising previous forms of production organisation (see above), the 'lean production system' was introduced as a response to structural limitations of the traditional factory model. Firstly, the traditional factory model is too rigid for responding to firms' increasing need to accommodate consumer preferences for product diversity and, as a result, to produce large varieties in small volumes. Secondly, given the scale and organisation in time of production stages, the traditional factory model is handicapped by large inventories and a relatively high number of defects. Thirdly, diversification in closely complementary but dissimilar activities, such as producing "a particular car with a particular brake and a particular brake lining" in the same factory (Richardson, 1972, pp. 891-892), requires increasing investment for building (or acquiring) new bundles of very specialised and diversified capabilities and, very often, a complete reconfiguration of the job specification programme.

The lean production system was pioneered by Toyota and resulted from the visionary ideas of its mechanical engineer Taiichi Ohno (Cusumano, 1985; Ohno, 1988; Fujimoto, 1999). The Toyota Production System invented by Ohno was based on two fundamental pillars: 'autonomation' and 'just in time' (JIT). The former, the introduction of 'autonomous machines' in production, opened up the possibility of reducing costs by eliminating waste of materials and machines' idle times. The JIT developed the idea according to which "in a comprehensive industry such as automobile manufacturing, the best way to work would be to have all the parts of the assembly at the side of the line just in time for their user" (Ohno, 1988, p. 75).

The application of these two principles resulted in the 'small-lot' production technique, i.e. a combination of the flexibility and high quality standards of craft production with the low cost of mass production techniques (Womack et al., 1990). This form of production organisation is characterised by higher levels of flexibility for two reasons: (i) the costs of switching from one product line to another are minimised and (ii) multi-task workers organised in teams are equipped with less highly specialised machines and tools than those used in the mass production factory model. The high quality standards of production are also made possible by the fact that every worker is allowed to stop production every time a fault is discovered (instead of assigning this decision to the senior line manager) and by the fact that product's components are supplied to the work station just in time (instead of keeping large stocks of each component beside the work station).

Although this organisational arrangement implies that initially stoppages in the production line are frequent, in the medium run workers are increasingly able to discover the sources of problems (and their interdependencies) in the space of capabilities, 'materials in use' and 'task execution'. These discoveries trigger a sequence of structural learning dynamics according to which solutions to a certain production problem or bottleneck are applied to similar problems. Additionally solutions to a particular production problem or bottleneck make the solution of complementary problems necessary. As the complementary production problems are identified and solved the number of stoppages diminishes to the point that they become much less frequent than in the typical mass production assembly line.

In the lean production system structural learning trajectories are also triggered by the fact that design teams work closely with production engineers and producers of product components. As a result the specification of product design proceeds hand in hand with the design, calibration and adaptation of tools and equipment that are used in production. In this way not only does the overall production system achieve high quality standards, but also in the product's design process a stream of diversified products rapidly develop. Thus the overall production system experiences reductions in the unit costs of production. The successful application in the Japanese car industry of this form of production organisation was at the centre of the International Motor Vehicle Programme started in 1979 whose results 
were collected five years later in the MIT book The Future of Automobile (1984).26

As is amply documented in Fujimoto's (1999) review of the evolution of the Toyota Production System and its transformation into the lean production system, these new forms of production organisation allowed firms to enter structural learning trajectories which were unfeasible within the traditional factory model. Indeed their discovery was the result of a structural learning dynamic in itself which involved precisely what we have called here intersectoral learning. In the words of Fujimoto (1999, p. 50 italics added) 'Toyota's production organisation [...] adopted various elements of the Ford system selectively and in unbundled forms, and hybridised them with their ingenious system and original ideas. It also learnt from experiences with other industries'. In particular, as reported in Cusumano (1985), Taiichi Ohno declared that "the automotive loom was a text book in front of [his] eyes". The application of the same solutions to similar production problems arising in different sectors was at the very root of the Toyota Production System and its evolution in lean production system or lean production technique. Throughout the 1990s lean production techniques were increasingly applied from the automotive to other industries such as aerospace, producing highly-complex products (Roos, 2003).

To recap, in all the above-mentioned cases, even if certain structural stimuli and feedback loops were to make certain structural learning trajectories feasible, only firms adopting a certain organisational form will be capable to follow these trajectories. Specific organisational features of production organisation may enable (or block) the three fundamentally alternative routes described above (structural learning trajectories triggered by discovering similarities, those triggered by discovering new complementarities and, finally, those triggered by overcoming indivisibilities).

\section{Concluding remarks}

Learning dynamics are the main transformative forces of economic systems. Economists have always been interested in this fundamental reality. Some recent studies have attempted to link micro-learning dynamics and macro-transformative effects by tracking countries' specialisation/diversification patterns driven by similarities in the 'product space', a network-type representation of the international market architecture (e.g. Hidalgo and Hausmann, 2009). However, these studies do not disentangle the different forms of learning realised at the firm level (as we have done in this paper) and thus are not able to explain how learning dynamics trigger structural change and economic growth of economic systems at different stages of development.

As learning processes are embedded in productive structures, any attempt to understand how economic systems change over time through learning dynamics cannot

\footnotetext{
${ }^{26}$ Among others see Bianchi's contribution on 'Flexible Manufacturing and Product Differentiation in the automobile industry'.
}

avoid looking at the reality of production processes. In this respect, the contribution of this paper is twofold. Firstly, building on structural theories dealing with the complex architecture of production, the paper has proposed a new heuristic for analysing interdependencies among components of production processes. The 'analytical map of production relationships' provides a stylised representation of the system of interrelated tasks through which transformations of materials are performed according to different patterns of capacities/capabilities coordination, subject to certain scale and time constraints. On this basis the two main forms of learning ('learning by doing' and 'learning by using') have been re-formulated in a way that sees them as being affected by and affecting the production structure.

Learning in production takes many forms and is realised at several interconnected (nested) levels, the pattern of nesting being structurally determined. Thus the concept of structural learning has been introduced to identify the continuous process of structural adjustment triggered and orientated by existing and evolving productive structures. The paper identifies three main structural learning trajectories. Static and dynamic complementarities, similarities and indivisibilities are essential triggers for activating compulsive sequences of technological change as well as for discovering new productive possibilities at the firm and interfirm level.

These structural learning dynamics have to be 'seen' by productive agents and 'used' by productive organisations. At this point, we have identifies a fundamental tension underlying structural learning dynamics. Namely, the fact that structures of production and structures of cognition are linked by a bundle of bidirectional transformative relationships. This tension is partially solved by the adoption of different forms of productive organisations, whose specific features may enable (or block) a number of structural learning trajectories.

From a methodological standpoint, in order to decompose the 'architecture of complexity' in production as well as investigate structural learning dynamics, the paper has maintained a 'separation' between two fundamental levels of analysis. At one level, the analysis focused on those dynamics inherent in productive structures independently of specific organisational/institutional configurations. At a deeper level, the analysis considered how, given certain possibilities embedded in productive structures, different organisations may follow different structural learning trajectories. The analytical account of specific historical cases has been adopted as the main heuristic for disentangling structural learning dynamics. At this point in the analysis the historical emergence and reappearance of different forms of productive organisation have been stressed.

Looking at the production process and its transformations from a structural perspective has allowed us to re-link production and learning dynamics. This goal has profound implications for policy design. Structural learning trajectories are transformative processes operating within the black box of production and, as such tend to remain 'invisible' to policymakers. The 'political economy of structural learning' suggests a number of unconventional policy options, such as the possibility of policy intervention in 
sectors, tasks and capabilities that are similar or complementary to those that were initially taken as the object of policy intervention. In this respect Silver (1984) argued that "in developing countries, or in developed economies when innovation renders the market's existing capabilities obsolete, a firm may have to integrate into many dissimilar activities in order to generate all the complementary activities it needs" (Langlois, 1992, p. 108; see also O'Sullivan et al., 2013). In economies in their catch-up phase, where constraints in production structures appear pervasive, the structural learning perspective also suggests possible strategies for overcoming indivisibilities or scale-invariant process constraints. Finally it points to the possibility of discovering unexploited opportunities embedded in existing productive structures at the sectoral and intersectoral levels, following patterns of diversification in similar activities, and building/exploiting technological linkages with those dissimilar activities towards the selective creation of new productive opportunities. The final aim of these structural learning policies is to facilitate the discovery of new 'worlds of possibilities' and, thus, the emergence of 'new 'worlds of production'.

\section{References}

Adler, P., Clark, K., 1991. Behind the learning curve: a sketch of the learning process. Manage. Sci. 37, 267-281.

Amit, R., Schoemaker, P., 1993. Strategic assets and organisational rent. Strat. Manage. J. 14, 33-46.

Andreoni, A., 2011a. Manufacturing agrarian change: intersectoral learning, technological capabilities and transformative policies, DRUID Working paper, 11-13.

Andreoni, A., 2011b. Productive Capabilities Indicators for Industrial Policy Design, UNIDO Working Paper, 17-11.

Andreoni, A., Scazzieri, R., 2013. Triggers of change: production structures and economic dynamics. Camb. J. Econ. http://dx.doi.org/10.1093/cje/bet034.

Andreoni, A., Gregory, M., 2013. Why and How Does Manufacturing still Matter: Old Rationales, New Realities. Rev. d'Écon. Indus. (forthcoming).

Altshuler, A., Anderson, M., Jones, D.T., Roos, D., Womack, J., 1984. The Future of the Automobile. The MIT Press, Cambridge, MA.

Atkinson, A., Stiglitz, J., 1969. A new view of technological change. Econ. J. $79,573-578$

Arrow, K., 1962. The Economic Implications of Learning by Doing. Rev. Econ. Stud. 29 (3), 155-173.

Babbage, C., 1835. [1832] On the Economy of Machinery and Manufacturing. Charles Knight, London.

Bell, M., 1982. Technical Change in Infant Industries: A Review of the Empirical Evidence. SPRU, University of Sussex (mimeo).

Bianchi, P., 1984. Divisione del Lavoro e Ristrutturazione Industriale. Il Mulino, Bologna.

Bourdieu, P., 1972. Outline of a Theory of Practice. Cambridge University Press, Cambridge.

Buenstorf, G., 2004. The Economics of Energy and the Production Process: An Evolutionary Approach. Edward Elgar, Cheltenham.

Buenstorf, G., 2005. Sequential production, modularity and technological change. Struct. Change Econ. Dyn. 16, 221-241.

Buenstorf, G., 2007. Complementarity, cognition and capabilities: towards an evolutionary theory of production. In: Ioannides, S., Nielsen, K. (Eds.), Economics and the Social Sciences. Edward Elgar, Cheltenham, UK.

Cartwright, N., 1989. Nature's Capacities and their Measurement Clarendon Press, Oxford.

Chang, H.-J., 2002. Kicking Away the Ladder. Anthem Press, London.

Cohen, W.M., Levinthal, D., 1990. Absorptive capacity: a new perspective on learning and innovation. Adm. Sci. Q. 35 (1), 128-152.

Cusumano, M.A., 1985. The Japanese Automobile Industry: Technology and Management at Nissan and Toyota. Harvard University Press Boston.

David, P.A., 1966. The mechanisation of reaping in ante bellum Midwest. In: Rosovsky H. (Eds.), Industrialization in Two Systems: Essays in
Honour of Alexander Gerschenkron. Wiley, New York. Republished in David, P.A., 1975. Technical Choice, Innovation and Economic Growth. Cambridge University Press, Cambridge.

Dodgson, M., 1991. The Management of Technological Learning. De Gruyter, Berlin.

Dosi, G., Nelson, R.R., Winter, S., 2000. The Nature and Dynamics of Organizational Capabilities. Oxford University Press, Oxford.

Fujimoto, T., 1999. The Evolution of a Manufacturing System at Toyota. Oxford University Press, Oxford.

Garnsey, E., McGlade, J., 2006. Complexity and Co-Evolution: Continuity and Change in Socio-Economic Systems. Edward Elgar, Cheltenham, UK/Northampton, USA.

Georgescu-Roegen, N., 1970. The economics of production. Am. Econ. Rev. LX (2), 1-9.

Georgescu-Roegen, N., 1971. The Entropy Law and the Economic Process. Harvard University Press, Cambridge, MA.

Georgescu-Roegen, N., 1976. Energy and Economic Myths. Pergamon Press, New York.

Georgescu-Roegen, N., 1990. Production process and dynamic economics'. In: Baranzini, M., Scazzieri, R. (Eds.), The Economic Theory of Structure and Change. Cambridge University Press, Cambridge, pp. 198-226.

Gibbons, R., Roberts, J. (Eds.), 2011. Handbook of Organisational Economics. Princeton University Press, Princeton.

Henderson, R., Clark, K., 1990. Architectural innovation: the reconfiguration of existing product technologies and failure of established firms. Adm. Sci. Q. 35 (1), 9-30.

Hicks, J., 1969. A Theory of Economic History. Clarendon Press, Oxford.

Hidalgo, C., Hausmann, R., 2009. The building blocks of economic complexity. Proc. Natl. Acad. Sci. 106 (26), 10570-10575.

Hippel von, E., 1988. The Sources of Innovation. Oxford University Press, Oxford

Jacobides, M.G., Winter, S.G., 2012. Capabilities: structure, agency and evolution. Organ. Sci. 23 (5), 1365-1381.

Jovanovic, B., Nyarko, Y., 1995. A Bayesian learning model fitted to a variety of empirical learning curves. Brook. Pap. Microecon., 247-305.

Kline, S., Rosenberg, N., 1986. An overview of innovation. In: Landau, R. Rosenberg, N. (Eds.), The Positive Sum Strategy. National Academy Press.

Kellogg, R.T., 1995. Cognitive Psychology. SAGE, Thousand Oaks.

Lall, S., 1992. Technological capabilities and industrialization. World Develop. 20 (2), 165-186.

Landesmann, M., 1986. Conceptions of technology and the production process. In: Baranzini, M., Scazzieri, R. (Eds.), Foundations of Economics. Blackwell, Oxford, pp. 281-310.

Landesmann, M., 1988. Where do we go from here? Technical change and dynamics. Camb. J. Econ. 12, 169-177.

Landesmann, M., Scazzieri, R., 1996. Production and Economic Dynamics. Cambridge University Press, Cambridge.

Langlois, R.N., 1992. Transaction-cost economics in real time. Indus. Corp. Change 1 (1), 99-127.

Langlois, R.N., 2002. Modularity in technology and organization. J. Econ. Behav. Organ. 49, 19-37.

Landes, D., 2000. Revolution in Time. Clocks and the Making of the Modern World. Belknap Press of Harvard University Press, Cambridge, MA.

Leontief, W., 1928. The economy as a circular flow. Struct. Change Econ. Dyn. $2,177-212$

Leontief, W., 1947. Introduction to a theory of the internal structure of functional relationships. Econometrica 15 (4), 361-373.

Lissoni, F., 2005. The reaper and the scanner: indivisibility-led incremental innovations and the adoption of new technologies. Camb. J. Econ. 29, 359-379.

Loasby, B.J., 1999. Knowledge, Institutions, and Evolution in Economics. Routledge, London New York.

Lundvall, B.A., 1992. National Systems of Innovation: Towards a Theory of Innovation and Interactive Learning. Pinter, London.

Malerba, F., 1992. Learning by firms and incremental technical change. Econ. J. 102 (413), 845-859.

March, J., Simon, H., 1993. [1958] Organizations, 2nd ed. Wiley and Sons.

Ménard, C., 2004. The economics of hybrid organizations. J. Inst. Theor. Econ. 160 (3), 345-376.

Mokyr, J., 1990. The Lever of the Riches: Technology Creativity and Economic Progress. Oxford University Press, Oxford.

Mokyr, J., 2002. The Gifts of Athena: Historical Origins of the Knowledge Economy. Princeton University Press, Princeton.

Morroni, M., 1992. Production Process and Technical Change. Cambridge University Press, Cambridge.

Morroni, M., 2006. Knowledge, Scale and Transactions in the Theory of the Firm. Cambridge University Press, Cambridge. 
Mowery, D., Rosenberg, N., 1998. Paths of Innovation: Technological Change in 20th-Century America. Cambridge University Press, Cambridge.

Mukoyama, T., 2006. Rosenberg's “learning by using” and technology diffusion. J. Econ. Behav. Organ. 61, 123-144.

Nelson, R.R., Winter, S., 1982. An Evolutionary Theory of Economic Change. Belknap Press, Cambridge, MA.

Noble, D., 1986. Forces of production: a social history of industrial automation. Oxford University Press, Oxford.

Ohno, T., 1988. The Toyota Production System: Beyond Large-Scale Production. Productivity Press, Portland.

O’Sullivan, E., Andreoni, A., Lopez-Gomez, C., Gregory, M., 2013. What is new in the new industrial policies? Oxf. Rev. Econ. Policy, http://dx.doi.org/10.1093/oxrep/grt027.

Pasinetti, L.L., 2007. Keynes and the Cambridge Keynesians. Cambridge University Press, Cambridge.

Penrose, E.T., 1959. The Theory of the Growth of the Firm. Oxford University Press, Oxford.

Piore, M., Sabel, C., 1984. The Second Industrial Divide: Possibilities for Prosperity. Macmillan, New York.

Pitelis, C., Teece, D., 2009. The (new) nature and essence of the firm. Eur. Manage. Rev. 6, 5-15.

Poni, C., 2009. La seta in Italia. Il Mulino, Bologna.

Richardson, G.B., 1960. Information and Investment. Oxford University Press, Oxford.

Richardson, G.B., 1972. The organisation of industry. Econ. J. 82, 883-896.

Richardson, G.B., 2003. The organisation of industry re-visited. In: DRUID Summer Conference.

Rhee, Y.W., Ross-Larson, B., Pursell, G., 1984. Korea's Competitive Edge. John Hopkins University Press, Baltimore.

Roos, D., 2003. The Development of Engineering Systems at MIT Engineering Systems Workshop, MIT, October, Cambridge, MA.

Rosenberg, N., 1963. Technological Change in the Machine Tool Industry, 1840-1910. J. Econ. Hist. 23 (4), 414-443.

Rosenberg, N., 1969. The direction of technological change: inducement mechanisms and focusing devices. Econ. Develop. Cult. Change 18, $1-24$.

Rosenberg, N., 1976. Perspectives on Technology. Cambridge University Press, Cambridge.

Rosenberg, N., 1979. Technological Interdependence in the American Economy. Technol. Cult. 20 (1), 25-50.

Rosenberg, N., 1982. Inside the Black Box: Technology and Economics. Cambridge University Press.
Rosenberg, N., 1994. Exploring the Black Box: Technology, Economics, and History. Cambridge University Press, Cambridge.

Salais, R., Storper, M., 1997. Worlds of Production: The Action Frameworks of the Economy. Harvard University Press, Cambridge, MA.

Sabel, C.F., Zeitlin, J. (Eds.), 1997. World of Possibilities: Flexibility and Mass Production in Western Industrialization. Cambridge University Press, New York.

Scazzieri, R., 1981. Efficienza produttiva e livelli di attività: un contributo di teoria economica. Il Mulino, Bologna.

Scazzieri, R., 1993. A Theory of Production. Tasks, Processes and Technical Practices. Clarendon Press, Oxford.

Scazzieri, R., 1999. A Theory of resilient flow-fund linkages. In: Mayumi, K., McGowdy, J. (Eds.), Bioeconomics and Sustainability. Edward Elgar, North. USA.

Silver, M., 1984. Enterprise and the Scope of the Firm. Martin Robertson, London.

Simon, H., 1957. Administrative Behaviour. A Study of Decision-Making Process in Administrative Organisation. Macmillan, New York.

Simon, H., 1962. The Architecture of Complexity. Proc. Am. Philos. Soc. 106 (6), 467-482.

Simon, H., 1986. Rationality in psychology and economics. Journal of Business 59, S209-S224.

Simon, H., 1991. Bounded rationality and organizational learning. Organ. Sci. 2 (1), 125-134.

Smith, A., 1976[1776]. An Inquiry into the Nature and Causes of the Wealth of Nations, General Editors R.H. Campbell and A.S. Skinner; Textual Editor W. B. Todd. Clarendon Press, Oxford.

Stiglitz, J., 1988. Learning to learn, localized learning and technological progress. In: Dasgupta, P., Stiglitz, J. (Eds.), Economic Policy and Technological Performance. Cambridge University Press, Cambridge.

Teece, D., 1980. Economics of scope and the scope of the enterprise. J. Econ. Behav. Organ. 1, 223-247.

Thompson, P., 2010. Learning by doing. In: Hall, B.H., Rosenberg, N. (Eds.), Handbook of the Economics of Innovation. Elsevier, North Holland.

Usher, A.P., 1954. A History of Mechanical Inventions. Harvard University Press, Cambridge, MA.

Womack, J.P., Jones, D.T., Roos, D., 1990. The Machine that changed the World. Harper-Collins, New York.

Wright, T.P., 1936. Factors affecting the cost of airplanes. Journal of Aeronautical Sciences 3 (4), 122-128. 